\title{
SMART CONTRACTS AND THE PRINCIPLES OF THE LAW OF OBLIGATIONS
}

\author{
Alexey Yu. Churilov \\ Tomsk State University, Tomsk, Russian Federation
}

Introduction: the digitalization of public relations and the emergence of smart contracts have created the need to study what a smart contract is and whether it is subject to the general principles of the law of obligations. Methods: the methodological framework for the research is a set of methods of scientific knowledge, among which the main ones are the methods of historicism, consistency, and analysis. Results: the possibility of extending the principles of the law of obligations to the relations of the parties when they conclude a smart contract is analyzed. Conclusions: the conclusion is made about the extension of the principles of the law of obligations to smart contracts with the features due to the nature of smart contracts.

Key words: smart contract, contract, obligation, principle, performance of the obligation.

Citation. Churilov A.Yu. Smart Contracts and the Principles of the Law of Obligations. Legal Concept = Pravovaya paradigma, 2021, vol. 20, no. 1, pp. 113-117. (in Russian). DOI: https://doi.org/10.15688/lc.jvolsu.2021.1.17

\section{СМАРТ-КОНТРАКТЫ И ПРИНЦИПЫ ОБЯЗАТЕЛЬСТВЕННОГО ПРАВА}

\author{
Алексей Юрьевич Чурилов \\ Томский государственный университет, г. Томск, Российская Федерация
}

\begin{abstract}
Введение: цифровизация общественных отношений, появление смарт-контрактов породили необходимость исследования того, что представляет собой смарт-контракт и распространяются ли на него общие принципы обязательственного права. Методы: методологическую основу исследования составляет совокупность методов научного познания, среди которых методы историзма, системности, анализа. Результаты: проанализирована возможность распространения принципов обязательственного права на отношения сторон при заключении ими смарт-контракта. Выводы: сделан вывод о распространении принципов обязательственного права на смарт-контракты с особенностями, обусловленными природой смарт-контрактов.
\end{abstract}

Ключевые слова: смарт-контракт, договор, обязательство, принцип, исполнение обязательства.

Цитирование. Чурилов А. Ю. Смарт-контракты и принципы обязательственного права // Legal Concept = Правовая парадигма. -2021. - Т. 20, № 1. - C. 113-117. -DOI: https://doi.org/10.15688/lc.jvolsu.2021.1.17

\section{Введение}

궁

今ิ

Первое упоминание технологии блокчейн (Blockchain) можно обнаружить в работе, написанной человеком или группой людей под псевдонимом Сатоши Накамото (Satoshi Nakamoto), «Биткоин: пиринговая электронная денежная система». Задуманная в первую очередь для оперирования криптовалютой (Битко- ином), эта технология, благодаря ее особенностям, вышла за те рамки, которые изначально были задуманы создателем: коллегиальное принятие решений, хранение информации являются далеко не единственными примерами применения блокчейн-систем. В настоящее время блокчейн-технология получила свое применение практически во всех сферах экономики и до сих пор является предметом оживленных 
дискуссий в научном сообществе. Одним из самых обсуждаемых направлений использования блокчейна в настоящее время являются смарт-контракты. Несмотря на многочисленное количество работ, посвященных исследованию смарт-контрактов, до сих пор не выработано единого доктринального определения этого явления, а также не определена его правовая природа [10, с. 136].

На самом базовом уровне смарт-контрактом называется компьютерная программа (или компьютерный код), которая может быть заключена только с использованием технологии блокчейн $[7$, с. 23] или иной распределенной базы данных, функционирующей по тем же принципам, что и блокчейн.

\section{Природа смарт-контракта}

Относительно правовой природы смартконтракта до настоящего времени не сложилось единого мнения. Существует несколько основных позиций:

- отнесение смарт-контрактов к договорам $[12$, с. 33$]$;

- смарт-контракт является не договором, но способом его исполнения [9];

- смарт-контракт это лишь форма договора [2, с. 117];

- смарт-контракт является формой самозащиты права [16, с. 313].

Представляется, что смарт-контракт - это не самостоятельный договор, но договорная конструкция, конституирующими признаками которой являются: заключение и существование его в исключительно электронной форме в системе блокчейн или иной распределенной базе данных; автоматическое исполнение возникающего встречного договорного обязательства без необходимости отдельного волеизьявления сторон договора; невозможность его изменения после того, как он был размещен в сети блокчейн, даже по соглашению сторон $[15$, с. 26$]$.

\section{Смарт-контракты и принципы обязательственного права}

Поскольку смарт-контракт является сложной с технологической точки зрения моделью, необходимо определить, насколько использование ее сторонами будет соответство- вать общим принципам обязательственного права. Под принципами обязательственного права понимают основополагающие, фундаментальные положения, идеи, содержащиеся в нормах права, а также выработанные судебной практикой, являющиеся обязательными для всей подотрасли обязательственного права, в которых находят свое отражение признаки обязательственного правоотношения [4, с. 163]. Не вдаваясь в дискуссию относительно системы принципов обязательственного права, отметим, что традиционно к ним относят: принципы исполнения обязательства (надлежащее, реальное исполнение, экономичность исполнения, содействие сторон), принцип добросовестности, недопустимости одностороннего отказа от исполнения обязательства, а также, принцип свободы договора [3, с. 70]. Рассмотрим, как эти принципы реализуются при использовании сторонами конструкции смарт-контракта.

Принципы исполнения обязательства реализуются при исполнении обязательства, возникшего при заключении смарт-контракта, в полном объеме. Интересным является то, что существование смарт-контрактов и их автоматизированное исполнение в какой-то степени подрывают ставшую традиционной концепцию исполнения обязательства как сделки (или иного юридического действия, но в любом случае волевого [1, с. 59]). Исполнение обязательства, возникшего из смарт-контракта, не требует отдельного волеизъявления стороны - все происходит автоматически, без необходимости дополнительных волевых действий сторон. Такая ситуация, помимо сугубо догматического характера, ранее могла вызвать проблемы при правоприменении, поскольку мог возникнуть вопрос - являются ли действия компьютерной программы исполнением обязательства, так как волевая природа исполнения требует наличия воли и волеизъявления. Эта проблема как минимум для целей правоприменения была решена внесением изменений в ст. 309 ГК РФ, в соответствии с которой условиями сделки может быть предусмотрено исполнение ее сторонами возникающих из нее обязательств без направленного на исполнение обязательства отдельно выраженного дополнительного волеизъявления путем применения информационных 
технологий. Однако правовая природа автоматизированного исполнения смарт-контракта подлежит дальнейшему подробному анализу.

Под принципом реального исполнения традиционно понимают необходимость исполнения обязательства в натуре, то есть совершения именно того действия, которое составляет предмет обязательства. Очевидно, что автоматизация исполнения смарт-контракта, позволяет обеспечить совершение именно тех действий, которые содержатся в коде программы. Более того, поскольку условия смарт-контракта невозможно изменить после его попадания в сеть блокчейн, гарантирует исполнение обязательства в строгом соответствии с условиями договора, так как компьютер не может отступить от заданных инструкций (при условии, что код смарт-контракта был сконструирован без ошибок).

Принцип надлежащего исполнения обязательства через следующие требования: исполнение обязательства надлежащим предметом, надлежащим способом, надлежащему лицу, надлежащим лицом, в надлежащий срок, в надлежащем месте. Природа технологии блокчейн и смарт-контракта подразумевает, что обязательство будет исполнено надлежаще в строгом соответствии с условиями инструкциями, которые закреплены в смартконтракте. Однако заблуждением будет полагать, что исполнение обязательства непременно является надлежащим, например, в случае поставки товара ненадлежащего качества, которая может иметь место при передаче объектов материального мира (вещей).

Экономичность исполнения обязательства достигается за счет той программной логики, которая заложена в самих компьютерных алгоритмах. Поскольку исполнение осуществляется посредством действия компьютерных алгоритмов, строгое алгоритмичное, последовательное, выполнение заранее определенных сторонами действий по исполнению должно предполагаться экономичным, пока не доказано иное.

Принцип содействия сторон в договорных обязательствах характеризуется совершением сторонами в интересах друг друга дополнительных действий, не предусмотренных договором, а предписываемых сложив- шейся конкретной ситуацией $[8$, с. 145]. Соблюдение этого принципа, как минимум на современном этапе развития технологий, затруднительно по той причине, что автоматизированная программа не способна совершить действия, не предусмотренные в инструкции. Однако стороны вправе самостоятельно, не вмешиваясь в действия программы, оказывать содействие друг другу для достижения цели обязательства.

Принцип добросовестности как необходимость учитывать сторонами законные интересы и права друг друга [11, с. 103] может найти свое проявление и при реализации сторонами смарт-контрактов. Проблема применения этого принципа к отношениям сторон смарт-контракта уже поднималась в отечественной литературе [5, с. 26]. Представляется, что этот принцип может быть реализован на стадии заключения смарт-контракта и согласования его условий. В частности, применение этого принципа должно быть направлено на исключение согласования сторонами несправедливых условий, которыми признаются условия, вызывающие значительное несоответствие в правах и обязанностях сторон, вытекающих из договора, в ущерб стороне договора, в нарушение требований добросовестности [13, с. 132]. После заключения смартконтракта, представляется, проявление недобросовестности сторон может заключаться лишь в препятствовании автоматического исполнения обязательства.

Принцип недопустимости одностороннего отказа от исполнения обязательства и изменения его условий находит полное отражение при использовании сторонами конструкции смарт-контракта. Техническая невозможность его отмены, безусловно, может породить ряд проблем для сторон, однако она гарантирует исполнение обязательства на тех неизменяемых условиях, которые были закреплены в нем сторонами. Неизменность содержания смарт-контракта как технического явления вызывает вопросы о возможности изменения содержания смарт-контракта как правового явления - договора. Как отмечают некоторые исследователи, невозможность отмены его технического исполнения лишь повлечет последующие взаиморасчеты [14, c. 32]. О каких «взаиморасчетах» идет речь 
в данном случае и как это связано с возможностью или невозможностью изменения условий смарт-контракта, не вполне понятно. Представляется, что невозможность изменения условий смарт-контракта на техническом уровне обусловливает невозможность изменения его условий как договорной конструкции. Вместе с тем сказанное не влияет на возможность суда признать такой смарт-контракт недействительным и применить последствия недействительности такой сделки с последующим исполнением сторонами реституционного обязательства. Трудно согласиться с исследователями, отрицающими возможность оспаривания смарт-контракта [2]. Смарт-контракт - не только технологическое явление, но и явление правовое - договор, который может быть признан судом недействительным. Невозможность изменения условий смарт-контракта может нивелироваться включением в него кода, позволяющего «уничтожить» такой контракт [6, с. 65] с последующим заключением смарт-контракта на иных условиях.

Принцип свободы договора как один из важнейших принципов обязательственного права распространяется и на отношения сторон по заключению смарт-контракта - стороны в праве выбирать: заключать смарт-контракт или же нет; выбирать его условия и контрагента; а также с учетом того, что смартконтракт является договорной конструкцией, выбирать тот вид договора, который они заключат с использованием этой конструкции.

\section{Вывод}

Подводя итог, можно сделать вывод, что, несмотря на особую технико-правовую природу смарт-контрактов, на них в полной мере распространяются принципы обязательственного права на всех стадиях договорного отношения: начиная от заключения договора и заканчивая его исполнением и прекращением.

\section{СПИСОК ЛИТЕРАТУРЫ}

1. Аюшеева, И. 3. Обусловленное исполнение обязательства в гражданском праве Российской Федерации / И. 3. Аюшева // Актуальные проблемы российского права. - 2017. - № 7. - С. 59-66.
2. Богданова, Е. Е. Проблемы применения смарт-контрактов в сделках с виртуальным имуществом / Е. Е. Богданова // Lex russica. - 2019. - № 7. C. $108-118$.

3. Вавилин, Е. В. Системность принципов и их действие в гражданском праве России и Китая / Е. В. Вавилин, А. А. Волос // Вестник Пермского университета. Юридические науки. - 2018. - № 1. - С. 53-73.

4. Волос, А. А. Понятие принципов обязательственного права / А. А. Волос // Вестник Саратовской государственной юридической академии. 2014. - № 3 (98). - С. 162-166.

5. Волос, А. А. Реализация принципа добросовестности применительно к отношениям сторон смарт-контракта / А. А. Волос // Право и цифровая экономика. - 2020. - № 2. - С. 26-31.

6. Ефимова, Л. Г. Применение технологии распределенного реестра для расчетов аккредитивами / Л. Г. Ефимова // Актуальные проблемы российского права. - 2020. - № 6. - С. 64-72.

7. Ефимова, Л. Г. Правовая природа смартконтракта / Л. Г. Ефимова, О. Б. Сиземова // Банковское право. - 2019. - № 1. - С. 23-30.

8. Захаркина, А. В. Факультативные обязательства по российскому гражданскому праву : монография / А. В. Захаркина. - М. : Статут, 2017. - 176 с.

9. Камалян, В. М. Понятие и правовые особенности смарт-контрактов / В. М. Камалян // Юрист. 2019. - № 4. - С. 20-27.

10. Матыцин, Д. Е. Цифровые технологии реализации гражданско-правовых сделок: договор репо на инвестиционные активы рынка ценных бумаг / Д. Е. Матыцин // Право и практика. - 2020. № 2. - С. 136-140.

11. Нам, К. В. Принцип добросовестности как правовой принцип / К. В. Нам // Вестник экономического правосудия Российской Федерации. - 2020. № 2. - С. 88-103.

12. Савельев, А. И. Договорное право 2.0: «умные» контракты как начало конца классического договорного права / А. И. Савельев // Вестник гражданского права. - 2016. - № 3. - С. 32-60.

13. Тордия, И. В. Принципы обязательственного права (международный и национальный аспекты) / И. В. Тордия, С. А. Савченко // Lex russica. 2016. - № 10. - С. 131-141.

14. Федоров, Д. В. Токены, криптовалюта и смарт-контракты в отечественных законопроектах с позиции иностранного опыта / Д. В. Федоров // Вестник гражданского права. - 2018. - № 2. - С. 30-74.

15. Чурилов, А. Ю. К проблеме понятия и правовой природы смарт-контракта / А. Ю. Чурилов // Юрист. - 2020. - № 7. - С. 25-30.

16. Werbach, K. Contracts Ex Machina/K. Werbach, N. Cornell // Duke Law Journal. - 2017. - Vol. 67. P. 313-382. 


\section{REFERENCES}

1. Ayusheeva I.Z. Obuslovlennoe ispolnenie obyazatel'stva $v$ grazhdanskom prave Rossijskoj Federacii [Conditional Fulfillment of an Obligation in the Civil Law of the Russian Federation]. Aktual'nye problemy rossijskogo prava [Actual Problems of Russian Law], 2017, no. 7, pp. 59-66.

2. Bogdanova E.E. Problemy primeneniya smartkontraktov v sdelkah s virtual'nym imushchestvom [Problems of Using Smart Contracts in Transactions with Virtual Property]. Lex russica, 2019, no. 7, pp. 108-118.

3. Vavilin E.V., Volos A.A. Sistemnost' principov $\mathrm{i}$ ih dejstvie $\mathrm{v}$ grazhdanskom prave Rossii i Kitaya [The Systematics of Principles and Their Action in the Civil Law of Russia and China]. Vestnik Permskogo universiteta. Yuridicheskie nauki [Herald of the Perm University. Legal sciences], 2018, no. 1, pp. 53-73.

4. Volos A.A. Ponyatie principov obyazatel'stvennogo prava [The Concept of Principles of Law ofObligations]. Vestnik Saratovskoj gosudarstvennoj yuridicheskoj akademii [Herald of the Saratov State Law Academy], 2014, no. 3(98), pp. 162-166.

5. Volos A.A. Realizaciya principa dobrosovestnosti primenitel'no k otnosheniyam storon smart-kontrakta [Implementation of the Principle of Good Faith in Relation to the Relations of the Parties to a Smart Contract]. Pravo i cifrovaya ekonomika [Law and Digital Economy], 2020, no. 2, pp. 26-31.

6. Efimova L.G. Primenenie tekhnologii raspredelennogo reestra dlya raschetov akkreditivami [Application of Distributed Ledger Technology for Settlements by Letters of Credit]. Aktual'nye problemy rossijskogo prava [Actual Problems of Russian Law], 2020, no. 6, pp. 64-72.

7. Efimova L.G., Sizemova O.B. Pravovaya priroda smart-kontrakta [The Legal Nature of a Smart Contract]. Bankovskoe parvo [Banking Law], 2019, no. 1, pp. 23-30.

8. Zaharkina A.V. Fakul tativnye obyazatel'stva po rossijskomu grazhdanskomu pravu: monografiya
[Optional Obligations in Russian Civil Law: Monograph]. Moscow, Statut Publ., 2017. 176 p.

9. Kamalyan V.M. Ponyatie i pravovye osobennosti smart-kontraktov [Concept and Legal Features of Smart Contracts]. Yurist [Lawyer], 2019, no. 4, pp. 20-27.

10. Matycin D.E. Cifrovye tekhnologii realizacii grazhdansko-pravovyh sdelok: dogovor repo na investicionnye aktivy rynka cennyh bumag [Digital Technologies for the Implementation of Civil Law Transactions: a Contract for Investment Assets of the Securities Market]. Pravo i praktika [Law and Practice], 2020, no. 2, pp. 136-140.

11. Nam K.V. Princip dobrosovestnosti kak pravovoj princip [The Principle of Good Faith as a Legal Principle]. Vestnik ekonomicheskogo pravosudiya Rossijskoj Federacii [Herald of Economic Justice of the Russian Federation], 2020, no. 2, pp. 88-103.

12. Savel'ev A.I. Dogovornoe pravo 2.0: «umnye» kontrakty kak nachalo konca klassicheskogo dogovornogo prava [Contract Law 2.0: "Smart" Contracts as the Beginning of the End of Classic Contract Law]. Vestnik grazhdanskogo prava [Herald of Civil Law], 2016, no. 3, pp. 32-60.

13. Tordiya I.V., Savchenko S.A. Principy obyazatel'stvennogo prava (mezhdunarodnyj i nacional'nyj aspekty) [Principles of Law of Obligations (International and National Aspects)]. Lex russica, 2016, no. 10, pp. 131-141.

14. Fedorov D.V. Tokeny, kriptovalyuta i smartkontrakty v otechestvennyh zakonoproektah s pozicii inostrannogo opyta [Tokens, Cryptocurrencies, and Smart Contracts in Domestic Bills from the Perspective of Foreign Experience]. Vestnik grazhdanskogo prava [Herald of Civil Law], 2018, no. 2, pp. 30-74.

15. Churilov A.Yu. K probleme ponyatiya i pravovoj prirody smart-kontrakta [To the Issue of the Concept and Legal Nature of a Smart Contract]. Yurist [Lawyer], 2020, no. 7, pp. 25-30.

16. Werbach K., Cornell N. Contracts Ex Machina. Duke Law Journal, 2017, vol. 67, pp. 313-382.

\section{Information About the Author}

Alexey Yu. Churilov, Candidate of Sciences (Jurisprudence), Analyst, Scientific and Educational Center "Intellectual Property and Intellectual Rights", Law Institute, Tomsk State University, Prosp. Lenina, 36, 634050 Tomsk, Russian Federation, Lefikantor@yandex.ru, https://orcid.org/0000-0001-9435-1626

\section{Информация об авторе}

Алексей Юрьевич Чурилов, кандидат юридических наук, аналитик научно-образовательного центра «Интеллектуальная собственность и интеллектуальные права» Юридического института, Томский государственный университет, просп. Ленина, 36, 634050 г. Томск, Российская Федерация, Lefikantor@yandex.ru, https://orcid.org/0000-0001-9435-1626 